УДК $1(091)+17.024$

DOI 10.18413/2712-746X-2020-44-3-411-419

\title{
Культурно-исторический смысл философии Гегеля
}

\author{
Лобастов Г.В. \\ Московский авиационный институт (национальный исследовательский университет), \\ Россия, 125993, г. Москва, Волоколамское шоссе, д. 4 \\ E-mail: lobastov.g.v@yandex.ru
}

\begin{abstract}
Аннотация. Логика Гегеля рассматривается автором как главное звено в его философии, имеющее объективное значение для культурно-исторического развития мышления, значение, выходящее далеко за рамки философии. Этим и утверждается объективный культурно-исторический смысл его философии. Задача конкретизирована анализом диалектической формы и демонстрацией ее истинности как метода. Сам метод понимается как деятельная способность, и тем самым смысл философии Гегеля сводится к удержанию в пространстве мыслительной культуры всеобщей диалектической формы, которая захватывает все содержание действительности и одновременно служит способом разворачивания внутренней логики этого содержания. Развернуто понятие истины как центральной проблемы философии и обоснована ее диалектическая форма, находящая свое выражение в логике Гегеля. Обоснована и утверждена мысль, что диалектическая логика Гегеля адекватно может быть постигнута только как развитие собственной мыслительной способности.
\end{abstract}

Ключевые слова: логика, диалектическая форма, способность, понятие, чистая форма, идея, истина, абсолютное, субъектность понятия; понятие и свобода.

Для цитирования: Лобастов Г.В. 2020. Культурно-исторический смысл философии Гегеля. NOMOTHETIKA: Философия. Социология. Право. 45 (3): 411-419. DOI 10.18413/2712-746X-202044-3-411-419

\section{The cultural and historical meaning of Hegel's philosophy}

\author{
Gennady V. Lobastov \\ Moscow Aviation Institute (National Research University) \\ 4 Volokolamskoe shosse, Moscow, 125993, Russia \\ E-mail: lobastov.g.v@yandex.ru
}

Annotation. In the article, Hegel's logic is considered as the main link in his philosophy, which has an objective value for the cultural-historical development of thinking, a value that goes far beyond philosophy. The objective cultural-historical meaning of his philosophy affirms by this. The task is concretized by the analysis of the dialectical form and demonstration its truth as a method. The method itself is understood as active ability, and thus the meaning of Hegel's philosophy comes down to retention in the space of mental culture of a universal dialectical form, which captures the entire content of reality and at the same time serves as a way to unfold the internal logic of this content. The concept of truth as a central problem of philosophy and its dialectical form is substantiated, which finds its expression in Hegel's logic. The idea that dialectical Hegel's logic can be adequately comprehended only as development own mental ability.

Key words: Hegel; philosophy; logics; dialectic form; ability; concept; pure form; idea; true; absolute; subjectivity concepts; concept and freedom.

For citation: Lobastov G.V. 2020. The cultural and historical meaning of Hegel's philosophy. NOMOTHETIKA: Philosophy. Sociology. Law series. 45 (3): 411-419 (in Russian). DOI 10.18413/2712-746X-2020-44-3-411-419 


\section{Введение}

В исторической философской культуре есть фигуры, которые обойти нельзя и пройти мимо них тоже невозможно, - даже если они не стоят на пути, даже если о них ничего не знать: без них ощущение смысловой незавершенности будет сопровождать любое философское сознание, не лишенное критического внимания к действительности. Ни одно свое представление нельзя обосновать, не опираясь на суждения этих философов. Гегель как раз одна из этих фигур, если не сказать первая.

Факт заключается в том, что эта опора на суждения исторической философии не обязательно сознательная. Мы не знаем, на чьих плечах стоим, когда производим математическую операцию два плюс два. Истинная философия разворачивает перед сознанием фундаментальные основания человеческого бытия - именно те, которые ни «обойти, ни пройти мимо» которых нельзя. Нельзя, потому как они даны в пределах самой мысли, не как эмпирические факты, на которые можно натолкнуться или которые можно знать по некоторым свидетельствам. Сегодня слышим, что Маркс-де не знал того, что история показывает сегодня, и потому его теория исчерпала себя содержанием классического капитализма и т.д. И говорят это будто бы люди неглупые, но шустрость их ума, легко показать, не выходит за рамки эмпирической методологии. Они из тех, кто «жонглирует» фактами. Неслучайно потому возникла проблема самого факта.

Но форму теоретического мышления из самих фактов не выведешь, это показано всем историческим развитием философии, и Кант на этом поставил точку. Обосновав невыводимость всеобщих и необходимых определений из содержания опыта. Гегелевская логика в полной мере это обстоятельство учла и показала, что ее форма тождественна содержанию, что мысль только воспроизводит это содержание. Как она это делает - показано движением всех категорий логики Гегеля. Все действительное содержание находится в пределах мысли. А пределы мысли разворачивают диапазон всех возможностей этого действительного содержания. Движение же самой мысли в ее предельных формах замкнуто в диапазон от тождества до противоречия. Потому мысль захватывает полноту бытия. Включая самое себя. Поэтому логика всегда есть движение от начала предмета к его полному осуществлению. Следовательно, к абсолютной истине.

В мире есть вещи, бытие которых, как нынче могли бы сказать, самодостаточно. Они укоренены в абсолютном, в них - точка отсчета любого формообразования в мире, и даже неопытный глаз чувствует в них таинственную глубину мировых начал. Истинная красота не требует адвоката, религиозному сознанию не надо доказывать бытие бога.

\section{1. Истина и диалектико-логическая форма}

Но в этом мире оспаривается все - даже истина. Истина даже в своей обоснованной форме. И есть силы, способные истину представить противоположным смыслом. Хотя, казалось бы, именно истина есть единственное, что прочно удерживает в себе абсолютное содержание и обнаруживает себя своим собственным объективным бытием. И потому, кажется, не нуждается в обоснованиях и доказательствах.

Ибо есть вещи, которые своим бытием в полной мере выражают свою сущность. Это и есть истина, данная в самом объективно-реальном бытии. Истинная вещь. Истинная форма бытия. Через которую непосредственно «светится» ее сущность. Где сущность совпадает с очевидностью. Для чего нет иной меры, кроме самой себя. И что служит мерой для всего другого. Как шар в геометрии есть мера любого реального пространственного тела округлой формы. Как человек в пространстве общественной культурно-исторической действительности. Ибо в исторической действительности все прочие меры носят преходящий характер, или иначе, снимаемый мерой человека, его человечности. И потому эта мера должна быть дана сознанию. 
Но действительность обнаруживает себя далеко не только в истинных формах. Она может проявляться и в формах изломанно-изуродованных, более того, сами эти формы могут представлять себя содержательными моментами самой этой действительности. А потому иметь и свою определенную этими формами меру. Эмпирический метод познания относительности этой меры легко придает всеобщий характер. Это и служит основанием для утверждения относительности истины. В этих обстоятельствах и вязнет любая эмпирическая методология.

Логическая форма - в любом ее образе, не обязательно гегелевском, - всегда устойчивее фактической стороны дела, и именно потому, что ею факты снимаются. Потому, по мнению самого Маркса, метод, который он использует при исследовании буржуазного общества, сохраняет себя в анализах любого исторического содержания. Метод живет как всеобщая форма и за рамками содержания XIX века.

Чтобы отсечь возможность обвинения в некоем идеализме (ибо снять в понятии не значит снять в действительности), напомню, что понятие для Гегеля есть истинный субъект, вне которого история не совершает ни одного своего дела. Идея, по Марксу, становится материальной силой, когда овладевает массами. Однако абстрактной идеи недостаточно, идея должна быть развернута в понятии. Которым овладеть несколько сложнее, чем выразить некую интенцию потребности и действия. Понятие становится внутренним определением субъекта, субъект определяется в действительности через ее понятие.

Весь выявленный историческим философским познанием состав категорий суть диалектические моменты движения действительного содержания. И философскому сознанию не должно казаться, что изменчивая форма бытия не содержит в себе абсолютной основы. Один из тех, кого философское мышление обойти не может, Гераклит, в движении увидел покой, в изменении - неизменность, в противоречии - тождество.

И эти формы не просто кажущиеся, явившиеся только сознанию, но объективно сущие и претендующие на статус определяющих мышление форм, а потому и на истину. А истина, если она не находит своего основания в абсолютном, то она и не есть истина. Сегодняшнее сознание философии это фундаментальное обстоятельство не только не берет во внимание, но легко его обходит и даже агрессивно пытается проблему истины вывести за рамки своих анализов как «неистинную». Так что легко снимается в начале статьи высказанное положение о невозможности в философии обойти некоторые фигуры: обходят и даже не оглядываются, а Гегеля, может быть, в первую очередь.

Правда, Гегель - не та фигура, которая нуждается в адвокатах. Но некоторые прояснения смысла его философии внутри контекста современных философских концепций (и не только философских, на диалектическую форму гегелевской логики наталкивается любая наука) оправдывается самим объективным значением его логики. Гегель ведь дискредитируется не некими «ужимками ума», а построением таких концепций, где истина низведена до уровня сиюминутно значащих в том или другом отношении представлений, на которые опирается сознание и некое социальное действие. Истина предстает как сама по себе ничего не значащая конструкция, за которой не лежит никакого денотата. Это - в прямую противоположность гегелевской философии, которая обосновывает онтологический характер истины. Характер объективный, имеющий значение в составе самого бытия, - как особая форма бытийного содержания, абсолютно укорененная в абсолютном, и потому объективно различающая себя от преходящих, зависимых, внешне определенных форм самой действительности.

Любое утверждение отсутствия истины, как это делается, например, в постмодернизме, утверждается как истина - иначе было бы бессмысленно вообще что-либо утверждать. Таким образом можно оправдать и оправдывается многообразие философских представлений (систем), каждая из которых претендует на выражение истины. Гегель говорит: «Те, которые полагают, что они что-то сказали этим названием (философией Г.Л.), могут тем легче проклинать или благословлять многие философские учения, чем 
больше они склонны смотреть, как на свет солнца, не только на каждое скопище звезд, но и на каждое мигание свечки, или, иначе говоря, готовы провозглашать философией всякую популяризаторскую болтовню и воспользоваться этим, по крайней мере, для доказательства того, что существует так много систем философии и ежедневно одна вытесняет другую» [Гегель, 1993, с. 102].

Абсолютное же содержание схватывается только через противоположность бытия и небытия. Потому логика и обязана в своем развитии удерживать именно это противоположение и все особенности их, бытия и небытия, перехода друг в друга. В реальнодействительном бытии, казалось бы, сама истина превращается в свою противоположность, когда чистая форма «разрушается», когда порядок превращается в хаос, а «из хаоса образуется порядок», когда единичная изломанность оказывается основанием и началом бытия «прекрасной» формы, когда сама красота оборачивается злом, когда зло превращается в благо.

Но здесь не только кажимость, здесь логика движения самой истины: истина не обособлена от своей противоположности, но, именно как истина, снимает свою противоположность в себе. Ясно, что мыслящему сознанию, привыкшему к рассудочной упорядоченности, не так легко удерживать себя в движении этих взаимоопределений.

Гегель уловил в этом «мутном потоке» действительности и ее отражений в сознании устойчивые формы. Принявший в себя все идеи Гераклита, Гегель в историческом движении сменяющихся форм, в переплетении причинности и исторической свободы, увидел логический порядок его внутренней формы. И показал внутреннюю подвижность, изменчивость этой устойчивой логической формы.

Потому логическая форма, представленная Гегелем, выглядит весьма необычно. Попробуйте увидеть в ней то, что традиционно излагалось и излагается в логических трактатах! Но неискушенному в философии сознанию только в «Субъективной логике» Гегеля увидится собственно логическое содержание. Разумеется, любую объективно представленную вещь легко разложить на составляющие ее части, и можно не в одной из них не увидеть целого. Это историками философии легко делается с любой философской системой. Попробуйте усмотреть в «Философии истории», в «Политических произведениях», в «Философии духа», в «Эстетике» и т.д. логику Гегеля! А в «Капитале» Маркса его метод?

Логическая форма - как форма движения самого содержания. Увидеть в этой логике что-то похожее на традиционную ее форму просто немыслимо. Хотя ведь и кажется, что в субъективной логике Гегель воспроизвел все основные формы мышления, как они прописаны со времен Аристотеля. В сфере бытия и сущности идет такая связь взаимоопределений и переходов, что может показаться сплошной мистикой. Система логики, пишет Гегель, - это царство теней, мир простых сущностей, освобожденных от всякой чувственной конкретности» [Гегель, 1970, с. 113]. Но попытайтесь удержать вниманием это движение, и будет понятна мысль Гегеля, что изучение этой логики приучает «вращаться в абстракциях и двигаться вперед с помощью понятий без чувственных субстратов, становится бессознательной мощью, способностью вбирать в себя все остальное многообразие знаний и наук в разумную форму, схватывать и удерживать их суть» [Гегель, 1970, с. 113]. Эта «мистика» выражает движение нашей субъективности в объективном материале, вхождение мысли, нашего сознания в действительность, обнаружение самим этим сознанием, что это движение и есть движение самой действительности.

Здесь тождество бытия и мышления, действительности и мысли (идеи). Для Гегеля мысль - это как раз определение самой действительности, это форма внутренней взаимосвязи определений содержания в его развитии, - что и предстает формой движения человеческой субъективности.

Понять гегелевскую логическую идею можно только как воссоздание вместе с Гегелем формы внутреннего движения содержания. А истинная форма есть тождество явления и сущности, возможности и действительности, объективного и субъективного, содер- 
жания и формы, свободы и необходимости и т.д. Всего известного ряда категорий. Говоря языком Гегеля, истинная мысль в своем движении следует выражающим ее моментам развивающейся идеи.

Да, во всех попытках дискредитировать философию Гегеля есть нечто недопонятое. Более определенно - недопонято именно зерно его философии. Мировая философская критика, естественно, за два века уже успела указать на все пороки его философии и, одновременно, на все его достоинства, и нет необходимости все эти позиции воспроизводить. Они захватывают диапазон от полного согласия до полного отрицания. Достаточно указать на И. Ильина и М. Хайдеггера.

И может показаться, что любая апология Гегеля с необходимостью находится внутри этого диапазона. И с этим спорить сложно. Но дело не в этом. И даже не в том, что содержательно нельзя не повторить массы тех суждений о философии Гегеля, которые в мировой философской культуре о нем высказаны: это необходимое следствие исторического культурно-философского процесса, в котором присутствует не только принцип кантианской критики оснований выдвигаемых позиций (парадигм, сказали бы сегодня), но и уже ставшее бессознательным, в этой критике отшлифованным, движение самих критикуемых форм. Гегель - так или иначе, - но уже вошел в способ нашего мышления и утонул в его бессознательных формах, - утонул настолько, что и психология бессознательного его там уловить не может. Что и понятно: извлечь из нашего субъективного содержания описанные Гегелем формы можно только с помощью его же логики. Однако там, где мышление хотя бы чуть-чуть совпадает с объективным движением мыслимого содержания, в этой же мере оно совпадает и с логикой Гегеля.

Bce, что Гегель выявил и представил в сознательных формах, открыто-доступных человечеству, остается за рамками сознания. Это совсем не противоречит только что высказанному суждению о присутствии в духовной культуре гегелевского способа мышления. Ибо это логическое содержание объективно, но существует как действенная форма бессознательной человеческой субъективности.

Гегелевская философия требует принципиального понимания, понимания ее принųuna, тогда она приобретает реально-действенный - и не только теоретический, но и практический - характер. Вряд ли будет умным опереться, скажем, на состав субъективной логики Гегеля, не сняв своей способностью логику бытия и сущности. Как угодно ссылайтесь на Гегеля, но, если в своем исследовательском движении вы не воспроизведете, не выразите своим движением всеобщую форму гегелевской логики, ни своего ума, ни объективной истины вы не обнаружите.

А что это значит - выразить и воспроизвести логику Гегеля? Если одним словом, то выразить предмет в его истине, во всех его категориальных определениях.

Гегель именно категории видит в качестве всеобщих закономерностей бытия мировой действительности. В этом отношении Гегель действительно панлогист, ибо утверждает тождество логических форм и форм бытийных. И столь же отчетливый спинозист, потому как его логика и есть выражение бытия «божественного» духа. Его логика универсальна, и предельные определения ее форм захватывают любое содержание, ибо понятие обязано выразить всю полноту содержания, и она, эта логика, выражает внутреннюю форму этого содержания, логику развития и бытия вещи. Но и Гегель - материалист: субъективная сфера понятия у него с необходимостью порождается диалектикой бытия, диалектикой, «выворачивающей» его сущность, и оборачивающейся понятием. В котором как раз бытие в его сущностных определениях и представлено. Скажете, это не есть отражение?

Именно отражение, но только не в тех примитивных формах, которые рисует нам столь же примитивный догматический (вульгарный, прагматический, позитивистский) материализм, изготовляемый для примитивной педагогики высшей школы. 


\section{2. Разум и действительность}

Еще предстоит войти в ту культуру мысли, которая так четко и даже лаконично выражена в логических произведениях Гегеля. Но и самому автору было понятно, как далека действительность от разумного бытия, от самой способности войти в истину. Казалось бы, здесь противоречие: у Гегеля ясно прочитывается мысль, что все действительное разумно, а я допускаю как будто нелепое утверждение, что действительность еще далека от разума. Да и приписываю это представление самому Гегелю.

Здесь, однако, требуется не забыть, что и все разумное действительно. Диалектику этих моментов мышление должно удержать, и только тогда оно не выпадет в односторонность своего суждения. И если еще мыслящее мышление увидит в логике Гегеля завершенную в себе систему от бытия и ничто до абсолютной идеи, удерживающей в себе полноту определений всего состава действительности, то будет понятна и мысль, что в каждой точке бытия осуществляется, как процесс и как сохраняющая себя конкретноустойчивая форма, вся полнота логических определений. Это, может быть, нелегко понять, но понять надо. Что возможно, только пройдя школу Гегеля.

Мощь ума, которую мир с самого начала признал в Гегеле, - увы! - осталась за рамками истории. Но не будет умным думать, что его диалектика, через Маркса и Ленина врезавшись в действительное бытие, обнаружила свою немощь. Скорее мир обнаружил свое бессилие удержать эту диалектику. Приземленность полуживотных мотивов эмпирического бытия и чистый разум кажутся мало совместимыми даже опосредствованным образом. Прагматичность настроений, нищета и богатство создали ситуацию, в которой не до высоких смыслов и соответствующих им идеалов, - разум едва успевает, если успевает, отразить и удержать то, что делается самой историей. Сова Минервы остается в сумерках. Более того, разум далеко не всегда понимает свой собственный продукт, свою собственную историю. Разум и действительность тождественны, но тождественны как противоположности. И реальное бытие содержит в себе этот момент истины, и содержит в реально-объективной форме, на которую действительное историческое развитие бессознательно опирается. Вывести бессознательную форму движения разума в форму самосознающего разумного бытия и есть смысл истории.

В логике выражено историческое развитие человеческого духа, объективный исторический процесс, понятие действительности предстает через логику ее развития. И нет иного способа достичь истины и тем самым истинного бытия, кроме осуществления той формы движения, которая содержится в понятии. Именно понятие, по Гегелю, определяет субъектность.

И, однако, наоборот, только в истории понятие выявляет свои истинные определения. И там, где субъективный дух не способен извлечь (вывести) понятие из действительности, он действует как несвободный, как ограниченный своей собственной неистинностью.

Свободный же в себе - значит осуществляющий себя в чистой логике понятия, по Гегелю, это в его Логике. В диалектике. Именно диалектика содержит в себе импульс активности, ибо это логика саморазвивающегося содержания. Обособляясь, она обретает свою чистую идеальную форму и существует только как объективный момент предметнопреобразовательной деятельности. И становится активной формой деятельности человека. Как абстрактно-отвлеченная всеобщая форма деятельности, она свое первое выражение и обособление получает в языке.

И здесь Гегель прав. Ибо бытие мышления с его логикой в качестве момента внутри реально-объективной деятельности не есть обособленное его бытие. Это - процессуальное бытие деятельной логической способности, непосредственно осуществляющей себя в предметном материале и весь этот материал превращающей в форму своего объективного движения. Здесь их, бытия и мышления, непосредственное тождество: все действительное разумно, все разумное действительно, повторю снова эту мысль. 
И еще раз укажу, что несовпадение разума с действительностью для диалектики банальная вещь, ибо там, где противоположности не способны отождествиться, а тождество развернуться противоречием, - там диалектикой не пахнет. Там попахивает простой ссылкой на факты, - и делается это именно там, где требуется логика. Любой дурак может показать математику камень и утверждать, что это не шар. И математик поймет, с кем имеет дело.

Мышление противополагает себя бытию и в этом самом бытии удерживает себя в материи такого рода, которая абсолютно не имеет значения ни для самой мысли, ни для смысла осуществляющейся практической деятельности. Материя творимой предметной культуры, которая, хотя и выступает исходным «языком реальной жизни» (Маркс) и противоположена субъекту, не может выступить условием свободного движения мышления, потому как смысловая сторона этой предметной культуры достаточно строго определена объективно-практической жизнедеятельностью. Именно поэтому для Гегеля материей отвлеченного свободного мышления является материя языка.

И в этом, повторю, есть момент истины, потому что в объективном процессе природно-исторического бытия логика связана особенным содержанием и не проявлена в чистом виде, понятие еще не извлечено из бытия и потому не дано сознанию в чистой, т.е. истинной форме. В пространстве языка мысль получает свободу и способна определиться в соответствии с обстоятельствами, увидеть свою собственную универсальность и, одновременно, свою определенность реальными объективными условиями. Увидеть идеальное содержание всего состава действительности, представленного в субъективности. И именно благодаря этому различию реального и идеального положить деятельность, воплощающую свою идею (цель) в действительность.

Понятие, по Гегелю, есть субъект. Мы бы сказали: понимание есть атрибут субъектности и тем самым не выразили бы полноты истины, что субъект исчерпывается своими атрибутами. И потому же, согласно Гегелю, понятие есть свобода, т.е. снятие объективности в ее природном бытии, и деятельность в сопряжении с ее, объективности, собственной логикой, т.е. логикой понятия, - поскольку в этой логике бытие представлено.

Не будучи способно преодолеть сопротивление бытия, понятие, однако, вынуждено примириться с действительностью и понять последнюю как свой предел. То есть как внешнее его определение, которое, поскольку понятие выражает именно действительность, есть одновременно внутреннее. Понятие зависит от действительности. Так как оно выражает ее, и только ее. Развитие понятия связано лишь с развитием действительности. В ней его предел. Логическая же форма понятия свой предел находит в абсолютной форме. Потому логическая мысль всегда и отрабатывалась через анализ своих собственных абсолютных пределов.

Только будучи высвобожденным из самой действительности, понятие способно к определению самой этой действительности. В реальном бытии, в своем эмпирическом движении «сослагательное наклонение» есть имманентная форма, ибо мыслящий момент реальной деятельности форму условия всегда держит в своем сознании. Иначе это и не была бы свободная деятельность. То есть не была бы деятельностью, которая сама себя обусловливает. Иначе говоря, ищет и создает себе условия и организует их в соответствии со своей целью. Потому и «сослагательность» есть имманентный момент исторического процесса.

История же делает это стихийно. Она есть, по Гегелю, движение к сознанию свободы, которая становится действительной только вместе с понятием.

И если чистая мысль, высвеченная гением Гегеля, все никак не может стать субъективным условием исторического действия, то вина ли тут Гегеля? И есть ли это основание для утверждения неистинности его логического учения? Тем более со ссылкой на марксистское движение в мире, которое, якобы, показало утопичность попыток «выпрыгивания» человека за рамки цивилизованных форм животности буржуазного общества? 
Если понятие не знает потенций бытия, оно не удерживает целого. А это значит оно и не есть понятие. Когда суждение осуществляет сама действительность - до понятия и за рамками сознания, вне «сослагательности» - в логике своего собственного движения, налицо процесс, который любая философия обозначает как материализм. И понятие, идущее «вослед», «сова появляется в сумерки», уходит в основание, и полагает процесс таким, каким видит.

Но ведь именно понятие есть истинная, т.е. свободная, основа исторического движения: идея, овладевшая массой, становится материальной силой (Маркс). Ибо человек, и только человек, есть истинный субъект. Стихийная история - история движения неосознанных и неразвернутых в сознании идей.

Кажется ясным, что сами идеи порождаются противоречиями реального материального бытия. В логике же Гегеля представлена именно идея, идея в ее чистой форме, т.е. как чистая потенция, в себе самой содержащая мотив, как способность осуществления себя в бытии. Но эта идея у Гегеля развернута не только в своей субъективной форме, а именно как объективный процесс движения действительности, порождающей субъективное понятие, дорастающее до абсолютного знания, и в этом своем образе, уходящем в основание. Разве не истинный образ бытия (во всяком случае, образ, всегда претендующий на истину) лежит - должен лежать! - в основании любого акта человеческой деятельности - от примитивно-прагматического до всемирно-исторического!?

\section{Заключение}

Философия - это наука о том, как возможна истина. Наука - это труд понятия, адекватная форма развития которого дана именно в «Логике» Гегеля. Именно эта Логика позволила Марксу погрузиться в экономическую реальность общественного бытия, именно поэтому «нельзя понять Маркса, не проштудировав всей Большой логики Гегеля» (Ленин).

Развернутая Гегелем логика самосознающей идеи есть отвлеченно-абстрактное знание, и как таковое в своей объективно-обособленной форме безразлично к субъективно-личностной деятельности человека. Хотя как раз эту деятельность и выражает. Гегель показал, что эта идея, ее логика, мышление, находит себя не только в теоретической абстракции, не только в текстах и ученых головах логиков, но и как объективно-идеальная форма, существующая вне и до сознания. И что всякая субъективно-психическая деятельность, претендующая быть умной, осуществляется по мере снятия этой абстрактности, т.е. по мере присвоения ее отвлеченно-отчужденной формы, превращения ее в собственную способность индивида. Более того эта форма (через субъективное ее восприятие) диктует индивиду поведение, выступает организующей его и управляющей им силой.

Принцип тождества бытия и мышления, сознательно и строго проведенный у Гегеля, отчетливо положенный в основание своих анализов Марксом, в современной философии представленный Э.В. Ильенковым в категории идеального, - мысль о тождестве объективной формы мышления и всеобщей формы культурно-исторической человеческой деятельности, конечно, не так легко понять, но это - требование самой действительности, желающей сохранить себя, тем более если удержать себя в разумных формах.

«...Философские представления, - говорит Гегель, - очень часто являются прямой противоположностью воззрению обычного представления» [Гегель, 1993, с. 100]. Эти слова Гегеля как нельзя лучше характеризуют сегодняшнее состояние этой науки, или, точнее, ту ситуацию, в которой философия как наука сегодня существует. Ибо истиной, как и во все времена, мало кто интересуется, и если бы она не была необходимым условием бытия, ее бы с удовольствием обходили. Ибо, как говорит Гегель, истина требует усилия ума, но не дана в созерцании. А ложно-иллюзорные формы сознания сегодня сто́ят больше истины. Ибо все превращено в товар. 
Разумеется, сегодняшняя ситуация дает мысли новый материал, но это совсем не значит, что он сам по себе способен как-то изменить позицию философии, - той, которая считает себя наукой и обосновывает себя как наука. Проблемы ее не снимаются, но поверхностный ум еще менее может их увидеть и выделить из преходящего богатого материала современности. А истина - как ведущая тема философии во все времена была актуальной формой в жизни человечества.

Именно в логике как внутренней способности постигающего истину ума заключен великий смысл гегелевской философии. Не дай бог в ней отыскивать такие образы, которые, примеряясь к действительности, обнаруживают себя не соответствующими ей. Да, ни окружность, ни треугольник не соответствуют ни одной предметной форме в мире. Но в полной мере соответствуют, есть выражение формы деятельности человека. И потому они есть идеальные формы деятельности, мышление. Логика Гегеля - это движение именно таких идеальных форм.

\section{Список источников}

1. Гегель Г.В.Ф. 1970. Наука логики: в 3 т. М., Мысль. Т. 1.

2. Гегель Г.В.Ф. 1993. Лекции по истории философии: в 3 кн. СПб.: Наука. Кн. І.

\section{ИНФОРМАЦИЯ ОБ АВТОРЕ}

Лобастов Геннадий Васильевич, доктор философских наук, профессор кафедры философии, Московский авиационный институт (национальный исследовательский университет); Президент Российского философского общества «Диалектика и культура»

\section{INFORMATION ABOUT THE AUTHOR}

Gennady V. Lobastov, DSc in Philosophy, Professor, Department of Philosophy, Moscow Aviation Institute (National Research University) MAI; President of the Russian Philosophical Society "Dialectics and Culture". 